\title{
Responsibility and the Ethics of Ecological Restoration
}

\begin{abstract}
This paper argues that the concept of responsibility can and should ground an ethics of ecological restoration. It starts with William Jordan's concept of restoration, namely the creation of mutually beneficial human-nature relationships. It builds a concept of responsibility using the works of Hans Jonas and Martin Drenthen, understood as a correlate of our technological capacity, as well as a relationship to the possibility of meaningfulness today and in the indefinite future. It is argued that we are responsible in a deep sense for engaging in projects of restoration in order to ensure the survival of embodied meaningfulness in the world.
\end{abstract}




\section{Responsibility and the Ethics of Ecological Restoration}

Do we have good ethical reasons for restoring damaged, degraded, or otherwise changed, natural environments? This is the question that I will try to provide an answer to in this paper.

Strong ethical reasons are concerned with directing human conduct over the indefinite future, whatever contingent uses of the environment might predominate at any given moment. So a strong ethical reason for restoring would both be applicable to any case, and give an a priori injunction to be open and receptive to future restoration. The term restoration has usually been employed to mean the bringing back of an environment to a previously existent state. This is, however, not its only use. Throughout its various deployments, there are two issue that the meaning of the term hangs on: what is meant by bringing something back, or rather, what is to be brought back, and how we understand the role of humans in this endeavor. In other words, one issue is that of the baseline to be used for restoration, while the other is of the meaning of human membership in the natural community. Though classically the baseline has been a previous ecological arrangement (a prairie, a marsh, and so on), the term has also been used to signify bringing back a kind of relation to the natural world (Jordan's ecological relationship, Jordan 1994, see below), or even bringing back (in an apparent paradox ${ }^{1}$ ) the autonomy of the natural world itself (Prior and Ward 2016). In these uses, humans are more likely to be seen as full members of the natural community, and not mere oppressors.

Restoration that is tied to specific baselines involves a nature/culture duality that I wish to sidestep. In baseline-specific restoration, it is the techno-logical culture that acts on nature in order to mould it, to make it do what it used to (see Katz's critique in 1). Instead, restoration as a relationship of autonomous parts has an important self-reflective component. What Oelschlaeger calls "a strong conceptualization of ecological restoration" implies "human self-conceptualization as much as it involves acting on the land" (Oelschlaeger 2007, 152). This mutual ecological relationship (see 1) is what I call restoration, and I do so because it reiterates human membership in the earth community

\footnotetext{
The paradox is apparent because it is not literally natural autonomy that can be brought back, but rather the perception of autonomy in the natural world. This is the sense in which self-willed land, though without a baseline, can nonetheless be thought of as restoration, inasmuch as it restores the perception of the natural world as an autonomous force.
} 
as well as the autonomy of the natural world. I therefore do not mean restoration as a technical tool, but rather as the basic approach toward the natural world that finds the use of such tools necessary for the creation of a kind of relationship.

The principle which will come to ground the ethics of restoration is that of responsibility. The bulk of the present argument will therefore spell out the elements of the concept of responsibility, and show precisely in what sense it imparts good reasons for restoring nature. In the process, I will argue for why responsibility is the best ground for an ethics of restoration, and situate this argument within broader debates. But first I wish to say more about the concept of restoration itself.

Whether ecological restorations can be ethical, under which conditions, and whether they involve dangerous moral hazard, has been the subject of much debate, ever since Elliot's 1982 publication of Faking Nature. There, Elliot argued that restorations in the classical sense do not, at least, have the same value as untouched nature. The origin of land in nonhuman agency is, for Elliot, a crucial part of the value of the land. Restoration cannot but modify the origin story in ways that diminishes natural value. Eric Katz $(1996,2009,2012)$ went further and claimed, in a series of publications that continue today, that restorations are always ethically problematic, because they perpetuate the dominating culture which gives rise to natural degradation to begin with. Furthermore, for both Elliot and Katz, the real danger of restoration is the promotion of moral hazard, namely the idea that we can destroy because we can later restore. As Basl expresses it, "the worry is that restoration, as opposed to preservation or conservation, will govern our decisions concerning natural areas" (2010, 137).

Restoration as baseline-specific does imply a techno-logical imposition on the natural environment, as it relies on an essentialist view of nature (as wholly independent) and of culture (as wholly dominating). As Deliège points out, Elliot's “argumentation against the restoration thesis requires that we agree with a strong ontological dualism between nature and culture" (Deliège 2007, 138). This kind of dualism misses something crucial, namely the evolutionary story of humans in the environment. Quoting Marjorie Grene, Oelschlaeger argues that "only if we place ourselves [...] without blatant contradiction, within nature, only then can we save the concept of historicity from the self-destruction to which it seems so readily susceptible" (in Oelschlaeger 2007, 151). If we understand humans as intrinsic parts of the natural environment, then the task is to understand how 
human actions can be made to coincide with ethical membership in a natural community. These essentialist positions on restoration have been countered by pragmatists, the most eloquent of which has been, in my view, Andrew Light (2000, 2001, 2009; Light and Higgs, 1996). He argues that restorations can be ethical, because in any given circumstance to restore is usually a choice between doing nothing or making a place better (understood in pragmatic terms). In other words, inasmuch as we can convert a parking lot back to a marsh (at least in functional terms), why not do it? This suspends judgment on the ethical merit of restoration given that it might deliver certain contingent goods.

In my view, neither the essentialist nor the pragmatist positions give us good reasons for restoring, or for abstaining from restoration. The position that treats nature as, preferably, an untouched, inherently valuable, other, sees restoration as either morally hazardous (at best), or as an extension of human domination (at worst). And the pragmatist position articulated in the work of Light finds itself in the awkward position of having to decide between better and worst uses of nature, with no criterion to help it do so. An alternative position has been advanced by William Jordan III, based on the potential of restoration to become a new paradigm for conservation and even for the environmental movement writ large. Jordan argues that "environmentalism, in its necessary defense of nature, $[\ldots]$ has by and large failed to come to grips with the problem of human interaction with nature" (Jordan 1994, 26). On this reading, Katz and Elliot's opposition to the idea of restoration assumes the desirability and possibility of having places completely untouched by humans. For Jordan, "preservation in the strict sense is impossible" (Jordan 2003, 14), which for him means that restoration in one form or another is unavoidable in an ethical interaction with nature. But what, exactly, is restoration in this sense?

"Ecological restoration is the attempt [...] to make nature whole" (Jordan 2003, 11). Read literally, this statement can be quite problematic (what does it mean to literally make nature whole?). On a metaphorical reading, making nature whole simply means interacting with natural environments in ways that recreate conditions of both human and non-human plenitude. Crucially, it means conceptualizing nature as inclusive of human membership: a whole nature is one that includes humans. To underline the meaning of what is surely a creative process better, he points out that restoration has been around for a long time. "In a general sense humans have been rehabilitating ecosystems altered or degraded by activities such as agriculture or tree cutting for millennia, through practices such as tree planting and the fallowing of land" (Jordan 2003, 12). To restore then is to relate to the land in a way that promotes the endurance of certain ecological processes and the 
self-conceptualization of humans as beneficial parts of the environment. This mutualism of the ecological relationship implies that restoration is a normative relation, that when humans relate to the environment as restorers they at the same time can improve their moral lot, by becoming beneficial members of a natural community.

This view of restoration supposes that humans are part of nature and therefore can participate in nature positively (Jordan 1990, Oelschlaeger 2007, Deliège 2007). Restoration need not be understood as replication, but rather as the continuation (or initiation) of a relationship with nature (always in the guise of a particular environment or landscape). The kind of relationship Jordan has in mind is one that he calls "ecological" (Jordan 1994, 18), and he means by that a relationship that is "mutually beneficial". Oelschlaeger, commenting on Leopold's land ethic, argues that "in acting upon the land we define ourselves ('writing' our signature)" $(2007,153)$. This is similar in important respects, because it opens the possibility of nature benefiting from our influence, just as we benefit from what nature has to offer.

In this view humans can become members of natural communities, not only mere users, which further implies that restoration projects need to engage with the human part of a natural environment. This engagement itself holds the promise of actualizing the potential of membership. In other words, it is not restoration itself, as Elliot and Katz argued, that perpetuates the domination of the natural world, but rather an understanding of restoration "as something humans do to the environment" (Oelschlaeger 2007, 152; he calls this 'weak restoration'). The weak view of restoration is predicated on a techno-logical relation to the natural world that intrinsically separates humans from nature, making the former agents deciding the fate of the latter. "A richer account of restoration should instead of reducing nature to the status of manipulable object, ensure that the natural space surrounding us transforms into a unique, meaningful place" (Deliège 2007, 137). This can both counter the norm-less application of technology (see 2 and 4), and give a new, ethical meaning, to our place in the natural world.

In the view of restoration as replication, the baseline to which one wants to return is of course highly important. In the relational view of restoration that this paper adopts, the baseline no longer features prominently. The issue of whether or not a baseline is to be followed at all is secondary to the idea of using restoration for the creation of meaningful human-nature relationships. So in some cases it might be that a baseline is useful for building membership in the biotic community. The University of Wisconsin Arboretum in Madison, one of the first modern restoration projects, 
initiated when Aldo Leopold was at the University in the 1930s, is an example of a baseline restoration ${ }^{2}$. However, in other places such restorations might be impossible, and then the existence of novel ecosystems (Hobbs et al 2006, 2009) can itself be seen as a possibility for creating meaningful relationships.

Starting from restoration understood as the building of a relationship, I want to propose in the rest of this paper that the concept of responsibility can offer a ground for restoration, as well as provide criteria for deciding between competing restoration projects or between restoring and doing nothing.

In what sense can we be responsible for non-human nature? Responsibility is generally understood to be commensurate with capacity. So if something is not within my reach, I cannot be responsible for it. Conversely, I am responsible for that which is within my immediate range of action. Here, I want to bring out a theme in Hans Jonas' work that theorizes responsibility in this way. I want to use his work on ethics, particularly as it is developed in his 1985 book The Imperative of Responsibility: in Search of an Ethics for the Technological Age and his 1984 article, Ontological Grounding of a Political Ethics. In these works, what occasions Jonas' thinking is our apparent technological power over the world, and thus the fact that the future of humanity can conceivably be endangered by present action. This is why ethics, as a theory of action, is needed, and particularly a future-oriented ethics that can answer the challenge of technological humanity. It makes sense that in the 1980s the possibility of destroying humanity would have been on Jonas' mind. Since then, this possibility has grown even more multifaceted. And though he is particularly concerned with the future of humankind, I want to switch focus to the future of nature, including humans but not restricted to them.

The main point of departure is that technology radically increases the future horizon that present decisions need to take into account. He argues that previous ethics was concerned with the future inasmuch as it was foreseeable, perhaps going as far as one's own children (Jonas 1985, 12-17). This was not a shortcoming of those ethical outlooks, but rather a response to the capacities of those times, when it was obvious that human nature would essentially stay the same, and that non-human nature would always essentially be an inexhaustible and fundamentally independent realm. These axes that ethics depended on were radically changed by technology. Indeed, we live in a time where

Also see 3 and 4 for a discussion of the Bronx River restoration project. 
both human and non-human nature are potentially affected by our decisions. Human nature can no longer be taken for granted, as it increasingly becomes the subject of technological tinkering (e.g Haraway 2008). Similarly, nature can no longer plausibly be conceived as infinite other, and therefore comes under the focus of present decisions in an unprecedented way ${ }^{3}$. Thinking nature as wholly other is unfit for dealing with modern, technological, capacities, and is itself a view of nature filtered through these capacities. Modern technology both posits nature as an object of alterity, and is incapable of regulating its relation to this foreign object. Under these conditions, ethics desperately needs to take into account the possibility of an indefinite future for human and non-human nature.

This starting-point leads Jonas to look for an ethical perspective that can cope with the pressure that technology has placed on our horizons of action. He does not wish the development of technology away, realizing that it would be futile, but rather attempts to meet it head on. This is not to say that he does not see room for wiser technological progress. The point, rather, is that technology can be considered a feature of human nature that we must reckon with whatever its manifestations. Though technology understood as tool use is a primary interface between us and non-human nature, technologos as it has developed in modernity (and as I use the term) lacks the guiding principles of mere tool use; it instrumentalizes and objectifies for its own sake - "the juggernaut moves on relentlessly" (Jonas 1979, 35) - which is also why it has written within itself the possibility of utter destruction. Another way to express this, getting us closer to the ethics I seek, is that scientific progress in the guise of technological development makes it imperative that there be norms, though it itself erodes all norms (Jonas 1985, 52).

Jonas expresses the predicament of an omnipotent but norm-less humanity thus: "now we shiver in the nakedness of a nihilism in which near-omnipotence is paired with near-emptiness, greatest capacity with knowing least what for" (Jonas 1985, 52). One way to react to our sometimes terrible encroachment on the world is to recoil in terror, claiming some essence of nature has been violated

The idea that pre-modern conceptions of nature regarded nature as inexhaustible is contradicted by anthropological studies (for example Berkes 2012, Anderson 1996, Turner 1981). What this body of work suggests is that in traditional societies a sense of the limits of nature is crucial and, partly because of its importance, internalized and transmitted through ritual. Jonas is partly guilty of underestimating the ways in which pre-modern societies had conceptualized nature as limited, and this I think for two reasons. First, his reference for pre-modern is the philosophy of European antiquity. Second, and related to the first, what he means by a conception of limitless nature (and unchangeable human nature) applies strictly to a conception of the world as such, and not necessarily to any of its constituent parts. Pre-modern societies had clear ecological limits ritualized, precisely because of their importance, but they in a sense overestimated how totalizing their world was. They were right, to be sure, given their particular histories. But so are moderns right in fretting about the possibility of destroying not just their particular world, but the world as such. 
and urging humanity to step back. This is indeed the response that Jordan identifies as the preservationist one. Jonas' direction cautions against this reaction, by underlying the duty to create norms able to deal with the application of technological power. The presence of "human intentionality and design" need not disqualify whatever posses its traces, but rather asks that there be norms that can direct its operations. This leaves open the possibility of human involvement in the natural world that willfully contains and directs technological power for ethical ends.

Jonas proposes to look at being in conjunction with the human consciousness that apprehends it. This human consciousness envelops both the possibility of annihilation through the norm-less application of science, and that of affirmation of life through moral imagination. For Jonas, the affirmation of life is grounded in ontology. He reads a teleological drive in being itself that demands recognition from consciousness. However, Jonas is only interested in the indefinite continuation of humans, and even then in their general continuation, that is to say without any qualification as to how future human life shall look in order to count as a proper human life. But if the affirmation of life is indeed ontologically grounded (also see Coyne, forthcoming), then there is nothing to limit our responsibility to future humans only. Seeing how responsibility cannot logically arise out of technology itself, it is in all cases a norm external to it and applied to it precisely because, without it, we risk annihilation. But inasmuch as the natural world also risks annihilation, there is nothing to stop us from applying the concept of responsibility as commensurate to capacity to the natural world as well. In other words, responsibility applied to nature as such and to its future existence only makes sense inasmuch as we are capable of radically impoverishing, if not outright annihilating, life. If this capacity were to disappear, so would our responsibility toward being as such. Similarly, if our capacity to destroy our own species would disappear, so would our responsibility for its indefinite maintenance. Conversely, previous non-technological humanity was not responsible in the same way.

Seeing how we have the capacity to destroy nature, we are bound by a bond of responsibility to its continuation. This, however, is not enough for a concept of responsibility that would be truly ethical, that is, that would give strong reasons for action. Jonas thought that "it is indeed of the very meaning of the normative principle that its call is addressed to recipients so constituted that they are by nature receptive to it (which does not, of course, already insure its being heeded)" (1985, 86). In other words, the call of responsibility arising from our capacity ${ }^{4}$ must fall on receptive ears in order

4 To be precise, for Jonas the call arises out of being itself. So responsibility has two layers here: one as the correlate to capacity, and the other as the response to the call of being that requires the affirmation of life. The first layer is fairly unproblematic. The second, however, would require a much lengthier discussion. It at least implies that 
to be heeded. This means that the individual receiving this call has to have an adequate moral receptivity. But even if this were the case, responsibility based on capacity would still lack the normative force we seek. Over and beyond the particular moral sensibility of individuals, the kind of technological power that we presently wield ${ }^{5}$ is hard to imagine and the damage it does is incremental. So, though our power is great, this is only so on aggregate; no individual human controls this collective power, which belongs to the human species. So for any given moral agent, the capacity of the species gives rise to a responsibility that is diffracted through its very remoteness. Though individuals chip away at the integrity of nature on a daily basis, the very chipping itself makes it hard to feel the responsibility of the species on one's shoulders. This means that relative interests are likely to trump long-term responsibility.

Focusing on long-term responsibility in light of technological power too easily leads to moralizing the actions of people that are merely trying to survive. We are tempted to make their actions cutting wood for cooking, poaching, irrigating - illegal and/or immoral because, on aggregate, they are indeed destructive. But this is both politically counterproductive and morally questionable. However, the concept of responsibility does not have to be limited to the sense we have extracted from Jonas' work. In the following, I will complement this basic meaning of responsibility as a correlate of capacity with other elements that, taken together, can offer a robust normative ground.

In order to present the next layer of the concept of responsibility, I need to attend to the meaning of nature. There are several different meanings of nature that are usually employed when speaking of restoration. Some restorations aim at the creation and/or enhancement of wilderness. Others are functional, and aim at the recovery of a particular ecological function, such as water filtration, through natural means. Others still refer to urban ecology, and want to enhance the ecological diversity and beauty of an urban space in order to make it more attractive for people. And finally, there are restoration projects which aim at the creation of "new nature" or what is also sometimes called (particularly in the Netherlands) "nature development" (Swart, van der Windt, Keulartz,

technology's dominion over human action is not total, such that individuals can respond to being based on intrinsic norms. This is shown to be the case empirically, and I see no reason why some form of feeling responsible for being inasmuch as it is purposive could not be part of the norms applicable to technological humanity. For a detailed analysis of the use of Jordan's ontology in environmental ethics, see Coyne, forthcoming.

5 This power is often characterized as absolute. However, absolute power implies absolute capacity, whereas what is truly frightening in the norm-less deployment of modern technology is that, precisely, nobody has the capacity to control it. In other words, technological annihilation is much likelier to be a mere mistake than a rational plan. 
But despite this diversity, there is an underlying meaning of nature that carries over through its diverse uses, namely the autonomy of self-made and/or self-willed processes of complex organization. In other words nature is that which precedes and survives us, the organization of life that, though responsive to human actions, does not need it in any fundamental way for its own endurance. Nature, though not itself a standard, provides the spontaneous background against which standards make sense. Nature thus conceived has always been fundamental for the creation of human meaning. In this sense, what we mean by nature will always be involved in a hermeneutical process.

"Environmental hermeneutics focuses on the fact that environments matter to people [...], because environments embody [...] [normative] contexts" (Drenthen 2013a, 17). From the hermeneutical point of view, nature is a text to be read (Clingerman 2009); indeed, it is the ultimate text, because it is at the same time the ground of our being, the region (Heidegger 1966) within which reading and meaning can happen. The normative context that Drenthen refers to in the quote above simply means that the natural environment provides a necessary background for the existence of human meaning and values. So whether we are speaking of the restoration of wilderness or that of an urban river, we can be sure that the meaning of those projects has to be understood in relation to the humans that are involved, and that those meanings change over time. This is perhaps best seen through the notion of nature that purports to be furthest removed from human meaning, namely wilderness. As Vicenzotti and many others (Oelschlaeger, 1991; Cronon, 1995; Schama, 1995; Vicenzotti and Trepl, 2009; Kirchhoff et al., 2013) have shown, "what is constitutive of wilderness are not the specific biophysical properties of an area but rather the specific meanings ascribed to it according to cultural patterns of interpretation" (Kirchoff and Vicenzotti 2014, 444). So it is then possible to catalog the meanings of wilderness through the ages, because "this interpretation of wilderness as not being a complex of ecosystems but a meaningful arrangement of symbolic objects renders visible the multitude of diachronic and synchronic meanings of wild nature: the way wilderness is viewed, characterized and valued is subject to change over time" (Kirchoff and Vicenzotti 2014, 445). Said differently, nature has to be understood as meaningful inasmuch as it plays a particular role in our life. But seeing how nature is the all-pervading text, it always plays meaningful roles in our lives, whether we are conscious of the fact or not, and no matter how apparently removed the particular concept of nature in question seems to be from human meaning. Ecological restoration then has the potential of drawing our attention to the fundamental role nature 
plays in the generation of human meaning ${ }^{6}$.

Another way of putting this point is that without human relations to nature, there is no culture. This being the case, we are justified in understanding restoration of nature as implicated in the restoration of human culture as much as of nature itself. Consider the effort currently underway to restore the Bronx river, flowing through the city of New York, USA. For centuries, it has been used as an open sewer. Industrial pollution, household waste, and raw sewage were all routinely dumped in a river that crosses poor and non-white parts of the city. The social dimension of the river's neglect is fairly clear. In 2005, the Bronx River Alliance started putting forward a vision for a restored river. This vision, which has attracted other partners and is currently being implemented, calls for the cleaning of the river's waters (so far, Alliance members have recovered over 600 tons of garbage from the river), the reintroduction of key species (for example, the oyster, which once thrived in the river and which could also help in the cleaning of the water through biofiltration), and the creation of a park along the river's watershed. This initiative is based on local participation; through it, local residents take control of their own emancipation and create for themselves a cleaner, more enjoyable, environment. Of course, in the process, the river itself becomes more ecologically sound. But the point I want to draw out of this example is in fact best summarized by a local participant in the cleanup operations (Jasmine Benitez) that was asked why she cares - why she shows up to clean the river every day. Her answer: "this is so important for me because this is home for me" (Al Jazeera 2013).

One way to understand the participation in restoration projects of this sort is through the idea of ritual. Jordan acknowledges the fact that many different kinds of rituals can exist, generating a variety of meanings (Jordan 2003). Indeed, restoration itself can become a ritualized form of engagement with nature, with the potential of delivering meaningful and mutually beneficial human-nature relationships. In the case of the Bronx river, the ways in which the natural environment plays a role in people's lives (before, during, and after restoration) is fairly clear; one further way to gage it is through Drenthen's concept of place. A place is not merely a spatial delimitation, but rather a meaningful landscape, what he calls a 'legible landscape', whose signs can be read by and be meaningful in human lives. So for the Bronx residents involved in the river restoration, the landscape has always been legible: the polluted river was a place that was read in

$6 \quad$ This is of course not the only activity that has this potential. For Leopold, hunting played a crucial role in the development of a land ethic. For Jordan, gardening offers a paradigm of interaction with the natural world that at the same time reveals the natural world as charged with meaning. I simply claim that restoration has a high potential to reveal the natural rootedness of meaning. 
terms of their overall exclusion from wider society; the restored river becomes a place marked with personal stories ("I put the first oysters there!") and symbolic of a wider social resistance, resurgence, and creation of dignity. The point is that, whether we engage in restoration or not, nature does not cease to be the ground of meaningfulness. A polluted river is just as legible as a healthy one; if we are not participants in the biotic community, we become users. What changes is not the fact of meaningfulness in interaction with nature, but rather the effects of that fact: a polluted river is alienating, a healthy one that I helped restore, mutually enriching.

This same analysis can be applied to a project that at first sight seem far removed from meaningfulness in this sense. The Dutch Oostvaardersplassen is an area of "new nature" located on land claimed from the sea. It aims to reconstruct a Pleistocene landscape, complete with proxy species for long-extinct ones: the Heck cattle in place of the Aurochs, and the Konik horse instead of the wild European horse. This kind of restoration - or rewilding, as it is also sometimes called did not happen where anyone lives, and has very little connection to any past extant in anyone's memory. However, the place generates an enormous amount of interest and debate every year in the Netherlands, particularly around the issue of culling (or not) animals in the winter. Whatever one thinks of the Oostvaardersplassen, it is clearly being incorporated in networks of meaning for many people. And though the two examples discussed are very different from each other, they both exemplify equally well how restoration in all of its guises always has to be understood in conjunction with the generation of human meaning. Nature and culture are not opposites; without one, there is not the other.

Today, most of us have no perceptible relation to anything natural: we live in completely humanmade environments. But this is an illusion, and a good starting point for making the concept of responsibility hit home is to show how we are always dependent on natural systems not only for resources, but for meaning too. Another way to gage the way in which "the natural" is fundamental for the creation of human meaning is to look at our modern obsession with animals. Animals here are, precisely, understood as stand-ins for that which is not human, the liminal other without which we have no sense of ourselves. If Shipman's (2011) paleoanthropology is to be believed, then our relations to animals have always been the fundamental driver in the evolution of specifically human consciousness (also see Tanasescu 2015). Today, we no longer paint animals on cave walls, but instead have pets that we lavish attention and care on. And Hans Harbers (2010) beautifully illustrates how the meaning of farming is inseparable from the meaning of animals in human lives and from the many ways in which an economy of care informs and enriches both human and non- 
human partners.

I want to point out how our natural inclination towards the non-human elements of our existence means that restoration projects themselves will of necessity become part of the hermeneutics of nature. "Landscapes can tell a story - a story that expresses the meaning that a particular landscapes can have for us, and that connects the story about the land with the story about us" (Drenthen 2013b, 17). Restoration itself becomes part of the meaning of a landscape, even where it aims at the erasure of the human footprint. So in a rewilded landscape, there is no reason why the history of restoration - the creation of the very space of wilderness - could not be part of a meaningful relation to the generated place.

What the above reflections suggest is that non-human nature, whether abstracted as a unitary whole or seen in its particulars, is fundamental to the generation and regeneration of culture. In other words, cultures are unthinkable outside of a multitude of relations with nature. Conversely, every time a particular part of nature disappears, a (cultural) meaning or practice is also irretrievably lost. Here we are coming close to the meaning of responsibility over and beyond its correction of outsized capacity. Inasmuch as we are responsible for the well-being of our fellow human beings and the survival of cultural networks of meaning, then we are also responsible for the nature that sustains such meanings. Conversely, the more homogenous the nature we create, the more homogenous our cultures will become. If the entire world would be a parking lot, the only meanings we would be capable of would be ones related to parking.

If we think it is good to aid the generation and regeneration of meaning in our lives, then responsibility for the natural environment is a necessary ethical outlook, which complements the argument from capacity and specifies it further. Yes, we are responsible because we can destroy, but we are also responsible for nature inasmuch as we are responsible for each other and for the possibility of heterogenous meaning in our lives. Responsibility for nature is the basis for cultural generation and regeneration without which human lives become increasingly less meaningful. This, then, points us toward the final elements of a concept of responsibility, namely owing future generations their own livelihoods, in cultural as well as other, terms. 
That we are responsible for the well-being of future generations is widely accepted, though it is usually understood in the narrow terms of classical sustainable development. The idea of sustainable development, arguably the dominant way of thinking our responsibility to future generations, involves leaving them enough to ensure that their future needs are met. This conception is entirely based on resources. So one could imagine the extraction of all humanly useful resources and their storage in such a way that they would be available, at the same rate, for ever. This, then, would count as sustainable. But of course, this would also mean that there would no longer be any forests, or mountains with coal within them. If one were to further insist on this hypothetical scenario being sustainable, something very odd would be going on, and an observer could rightly point out that future generation would be deprived of something else: a world of possible meaning that we currently enjoy.

At least since Locke we have, in theory, accepted some form of 'resource responsibility'. It is easy to understand why: if I cut down all trees, I prejudice my descendants, in that they can no longer have any trees for themselves. The dispute as to the non-identity problem (Parfit, 1984) does not concern the present argument, and I take it for granted that there will be future humans and that those will have needs and interests broadly similar to mine. But if the application of this kind of responsibility were to lead to a world of plantations, our descendants would also be prejudiced, though not in terms of resources narrowly understood; after all, plantations could provide them with the instrumental uses of trees. The reason for their being prejudiced nonetheless is that plantations as an embodiment of homogeneity (they are also called monocultures) - can only be read in so many ways. So what would have been robbed from future humans is the very possibility of relating to forests or, put in more general terms, to relate to nature in both heterogeneous and meaningful ways $^{7}$. Thus, if section (3) above is to be followed, the very possibility of regenerating their cultural meanings would be in danger. Whatever it is we currently do with forests that does not pertain to resource exploitation would no longer be a future option, and therefore a myriad cultural features that depend on forests for their existence would have become extinct. The implication here is that, if we think of the responsibility toward future generation in terms of meaning as much as in terms of resources, then we are responsible for leaving to future generations the relative freedom to have meaningful and varied relations to nature, and to regenerate their own cultural practices.

7 The same argument holds if, instead of sustainability, we take the example of cultural ecosystem services. As James (2015) has argued, not everything that nature provides can adequately be conceived of as a service. Indeed, what I here call the meaningfulness of nature in human lives cannot be thought of as a service. 
Another angle toward this argument can start from the meaning of resource: this notion needs to be understood as one particular relation to nature. Thinking the natural environment as resource is something that the natural environment itself, seen through the incessant thirst of our primal needs, suggests. When looking to cook, a branch offers itself as resource for cooking; an egg, as resource for eating. This is to say that what I mean by our responsibility for the future possibility of meaning is not opposed to the idea of resource, but rather to its dominance. This is because the idea of resource too easily colludes with the technological view that empties our relation to the natural environment of any ethical component, because the operations of technology itself are ethically unrooted. To relate to the natural world as resource only restricts the horizon of possible meaningfulness and, crucially, empties it of ethical purchase. In other words, we have no right to fix for future generation the one dominant way in which they shall relate to nature, because that would mean denying them the very possibility of generating new and diverse cultural meanings.

This view would imply ethical relativism if the hermeneutical approach was not complemented by the concept of restoration developed earlier. Hermeneutics itself is normatively agnostic: it simply tells us that meanings exist, and are generated in certain practices, but not how to prefer one over another, how to choose between competing versions. In order to normatively ground the hermeneutical approach, I need to reach back to the concept of restoration. It was argued that restoration is understood as the (re)creation of a mutually beneficial ecological relation, with two important parts: the natural world is recognized its autonomy vis-a-vis the human (it and only it can organize itself in the ways in which it does), and the human being, in seeing itself through the land, understands itself as part and parcel of the natural world, as a natural citizen, and as a potentially beneficial one. The mutualism of the ecological relationship pursued through restoration demands that we, at least, allow for future meanings that include the human being as a beneficial member of the earth community. Jordan's concept of restoration reconceived hermeneutically shows that in interacting with nature as restorers, we act both in service of nature (we benefit $i t$ ) and we reassess our own being as members of an earth community. This is to say that in ecological restoration conceived relationally, we have both ecological criteria for a restoration well done (biodiversity, functionality, and so on), and hermeneutical ones, that is, the extent to which humans involved in restoration come to see themselves as beneficial animals. Importantly, I think that these two kinds of criteria work together and reinforce each other: the more ecological goals are reached, the more one feels oneself a good natural citizen, and the more one creates a meaningful place with both human and natural components. Restoration can therefore become an ongoing practice, a 
continuous renewal of membership in the natural community (as opposed to an intervention when something is destroyed).

Does this imply that all forms of nature are to be restored? Not exactly. It is true that this view of responsibility applied to the practice of restoration does not give any a priori guidance as to which environments are to be restored. That choice is left to practical contexts, but one of the salient points of having adopted Jordan's version of restoration is that, as a practice of mutual beneficence, it necessarily involves the participation of those invested in a particular environment and their reconceptualization as members of a natural community. This further implies that it is through participatory means that what is to be restored should be decided, leaving open the theoretical possibility of any environment being the goal of restoration, whether historical or novel, genetically 'pure' or not, native or temporarily alien. It does not, however, leave open the possibility of ecological destruction.

A crucial part here is that technology, precisely in being itself norm-less, hides our evolutionary background. Inasmuch as we interact with the world technologically, we seem to be in control, as if masters of the universe ${ }^{8}$. This is a dangerous illusion because in the final analysis, we have no overarching insight into the organization of life, and what nature does effortlessly is a tremendous mystery to us. Inasmuch as we restore based on technology, we have no norms. However, if through restoration in Jordan's sense we also restore our place in the natural world as animals, we begin to see how an animal needs a world for its wellbeing, and how through this basic fact of embodied existence we can come to impose norms on our technological capacities. The concept of responsibility and a hermeneutically grounded restoration thesis gives us a strong ethical injunction to relate to the natural world in a restorative fashion, and to do so inasmuch as we can achieve a reconceptualization of the human being away from techno-logos and towards earth membership.

I am now in a position to sketch a fuller conception of responsibility that I think is apt for grounding an ethics of restoration understood as the creation of ecological relationships. The three layers forming the meaning of responsibility are our technological capacity and the possibility of heterogenous embodied meaning both in the present and in the future. So in each case where restoration is a question, we can ask ourselves: how is this case correlated with our capacity; how does it impact possible relations to the natural world; how does it impact future possibilities of meaning? Of course, these questions cannot be answered with any degree of certainty if one tries to

8 The dominance of this way of thinking is today easily seen in the purchase that the term anthropocene is gaining. 
answer from, as it were, the vantage-point of the future. But that is not what is needed. In the here and now, faced with a choice of restoring a particular place or not, the concept of responsibility presented here first and foremost accepts the very possibility of restoration as an option (something which Katz's position, for instance, does not). It is furthermore able to specify ways in which a restoration project can be ethically assessed, and the vantage of the future is not necessary because what is being left open is the future possibility of meaning within the general outlines of membership in the natural community (and so guarding against the norm-less application of technology). What is being restored is at the same time the possibility of future ritualization of the human-nature relationship, thus allowing for the possibility of a biotic community including all life, not all life minus humans.

Consider again the Bronx River restoration project. The blueprint for the restoration was drawn up using historical maps of the Bronx river that showed the extent of marshes and forests long gone (American Museum of Natural History 2012). This, then, would appear to be a baseline-specific restoration. But because the project is in the Bronx, a dense urban area, it is no longer feasible to use the maps as exact guidance for restoration. In other words, marshes will never cover their previous territory. In this context, the maps don't so much provide a baseline, as they give guidance specific to the river. In other words, based on historical data it can be ascertained what used to live in the river, and therefore we are in a better position to judge what could live there now, and what its impact might be. This is to say that the Bronx River restoration is a live example of a project that is only superficially tied to baselines. What it is really about is restoring the relationship between the community and the river. It is about remaking a biotic community.

The participation of the local community is crucial in this effort. It also shows the mutually reinforcing relationship between ecological and hermeneutical criteria: the more participants helped the river, the more they understood themselves as beneficial members of a community. The local volunteers speak about the fulfilling experience of participating in clean-up operations, plantings, or species release. Many had never been on any river before, let alone this famously polluted one. As one participant describes the restoration project, "this gave me an eight mile back yard" (Wildlife Conservation Society 2014). This doesn't mean that she is thinking about the river as her private property. Instead, she is living the river as a community asset, a place that is now filled with meaning, also because it has transformed her own self-perception. The Bronx river is her back yard not because it moved closer to her physical home, but because its meaning as part of a biotic community that includes her has been restored. As she then continues: "this is pretty personal". 
Community organizer and activist Majora Carter speaks about the first step in this project: "I had to help folks in the neighborhood understand that [...] there was a river here" (Al Jazeera 2013). Once the river becomes part of the local conscience, it can become embedded in systems of meaning that are also transformative for human self-perception. The meaning of the river as open sewer could not achieve the transformation of people into members of a larger community of life. Having left the river as an open sewer would have limited the future possibilities of community membership and cultural regeneration. From this perspective, the Bronx River Alliance is fulfilling its responsibility to restore.

Do we have good ethical reasons for restoring damaged, degraded, or otherwise changed, natural environments? Yes, and those are given by the concept of responsibility. Why are we responsible for the natural world? Because of our capacity, as well as (and perhaps especially) because our cultural meanings are a dialogue with the natural environment. Lastly, restoration understood as a relationship is a valuable way of creating much needed norms for the guidance of technology, and a sure way of understanding ourselves as part of a larger community of life. If this premise is accepted, then being responsible for our cultural meanings now, and for their future possibility, implies that we care for the natural environment. Without a rich nature, there can be no diverse cultures. And when the possibility of embodied cultural meanings depends on an environment being restored, then the ethics of responsibility asks that we restore. 


\section{Works Cited}

Al Jazeera English. 2013 October 10 ${ }^{\text {th }}$. Earthrise: Bronx River Revival. Retrieved from: https://www.youtube.com/watch?v=4zbuEM_ZzCA.

American Museum of Natural History. 2012 June $6^{\text {th }}$. Science Bulletins: Bronx River Restoration. Retrieved from: https://www.youtube.com/watch?v=tCClu3iTYIU

Anderson, E. N. (1996). Ecologies of the heart: emotion, belief, and the environment. Oxford University Press on Demand.

Basl, J. (2010). Restitutive restoration: New motivations for ecological restoration. Environmental Ethics, 32(2), 135-147.

Berkes, F. (2012). Sacred ecology. Routledge.

Clingerman, F. (2009). Reading the book of nature: A hermeneutical account of nature for philosophical theology. Worldviews: Global Religions, Culture, and Ecology, 13(1), 72-91.

Coyne, L. (forthcoming) Phenomenology and Teleology: Hans Jonas' Philosophy of Life. Environmental Values.

Cronon, W. (1995). 'The trouble with wilderness; or, Getting back to the wrong nature', in:

Cronon, W. (ed.) Uncommon ground, 69-90. New York: Norton.

Deliège, G. (2007). Toward a richer account of restorative practices. Environmental Philosophy, 4(1/2), 135-147.

Drenthen, M. (2013a). New nature narratives. Landscape hermeneutics and environmental ethics. In Clingerman, F., Treanor, B., Drenthen, M., \& Utsler, D. (Eds.). (2013). Interpreting Nature: The Emerging Field of Environmental Hermeneutics. Fordham University Press. 225-241.

Drenthen, M. (2013b). Landscapes devoid of meaning? A reply to Nicole Note. Environmental Values 23:1, 17-23.

Elliot, R. (1982). Faking nature. Inquiry, 25(1), 81-93.

Haraway, D. J. (2008). When species meet. Minneapolis: University of Minnesota Press.

Harbers, H. (2010). Animal farm love stories. Care in Practice: Tinkering in Clinics, Homes and Farms, 141-170.

Heidegger, M. (1966). Discourse on thinking. New York: Harper \& Row Publishers.

Hobbs, R. J., Arico, S., Aronson, J., Baron, J. S., Bridgewater, P., Cramer, V. A., ... \& Norton, D. (2006). Novel ecosystems: theoretical and management aspects of the new ecological world order. Global ecology and biogeography, 15(1), 1-7.

Hobbs, R. J., Higgs, E., \& Harris, J. A. (2009). Novel ecosystems: implications for conservation 
and restoration. Trends in ecology \& evolution, 24(11), 599-605.

James, S. P. (2015). Cultural Ecosystem Services: A Critical Assessment. Ethics, Policy \& Environment, 18(3), 338-350.

Jonas, H. (1979). Toward a philosophy of technology. Hastings Center Report, 9(1), 34-43.

Jonas, H. (1984). Ontological Grounding of a Political Ethics: On the Metaphysics of Commitment to the Future of Man. Graduate Faculty Philosophy Journal, 10(1), 47-61.

Jonas, H. (1985). The imperative of responsibility: In search of an ethics for the technological age. University of Chicago Press.

Jordan III, W.R. (1990). Two Psychologies. Restoration and Management Notes, 8(1).

Jordan III, W. R. (1994). Sunflower Forest': ecological restoration as the basis for a new environmental paradigm. In Baldwin, A. D., De Luce, J., \& Pletsch, C. (Eds.). Beyond preservation: restoring and inventing landscapes, U of Minnesota Press. 17-34.

Jordan, W. R. (2003). The sunflower forest: ecological restoration and the new communion with nature. University of California Press.

Katz, E. (1996). The problem of ecological restoration. Environmental Ethics, 18(2), 222-224.

Katz, E. (2009). The big lie: human restoration of nature. Readings in the Philosophy of Technology, 443.

Katz, E. (2012). Further adventures in the case against restoration. Environmental Ethics, 34(1), 6797.

Kirchhoff, T., Trepl L., and Vicenzotti, V. (2013). What is landscape ecology? An analysis and evaluation of six different conceptions. Landscape Research 38(1), 33-51.

Kirchoff, T., \& Vicenzotti, V. (2014). A historical and systematic survey of European perceptions of wilderness. Environmental Values, 23(4), 443-464.

Light, A., \& Higgs, E. S. (1996). The politics of ecological restoration. Environmental Ethics, 18(3), 227-247.

Light, A. (2000). Restoration, the Value of Participation, and the Risks of Professionalization. In Gobster, P. H., \& Hull, R. B. (2000). Restoring nature: Perspectives from the social sciences and humanities. Island Press. 163-181.

Light, A. (2001). The urban blind spot in environmental ethics. Environmental politics, 10(1), 7-35.

Light, A. (2009). Ecological restoration and the culture of nature: A pragmatic perspective. Readings in the Philosophy of Technology, 452.

Oelschlaeger, M. (1991). The idea of wilderness: From prehistory to the age of ecology. Yale University Press. 
Oelschlaeger, M. (2007). Ecological Restoration, Aldo Leopold, and Beauty: An Evolutionary Tale. Environmental Philosophy, 4(1/2), 149-161.

Parfit, D. (1984). Reasons and Persons. Oxford: Oxford University Press.

Schama, S. (1995). Landscape and memory. New York: Vintage.

Shipman, P. (2011). The animal connection: a new perspective on what makes us human. WW Norton \& Company.

Swart, J. A., Van Der Windt, H. J., \& Keulartz, J. (2001). Valuation of nature in conservation and restoration. Restoration Ecology, 9(2), 230-238.

Tanasescu, M. (2015). Speaking for Nature: representing the environment through rights. London: Palgrave Macmillan.

Turner, V. W. (1981). The drums of affliction: A study of religious processes among the Ndembu of Zambia. International African Institute in association with Hutchinson University Library for Africa.

Vicenzotti, V. and Trepl, L. (2009). City as wilderness: The wilderness metaphor from Wilhelm Heinrich Riehl to contemporary urban designers. Landscape Research 34(4), 379-396.

Weiss, E. B. (1990). Our rights and obligations to future generations for the environment. American Journal of International Law, 198-207.

Wildlife Conservation Society. 2014 November $3^{\text {rd }}$. Urban Waters: Restoring the Bronx River. Retrieve from: https://www.youtube.com/watch?v=xvTq2ynivZ4 